\title{
IMPLEMENTASI TEKNOLOGI VIRTUAL TOUR PADA MUSEUM
}

\author{
Ahmad Dedi Jubaedi ${ }^{1}$, Saleh Dwiyatno ${ }^{2}$, Sulistiyono ${ }^{3}$ \\ ${ }^{1,3}$ Program Studi Informatika Fakultas Teknologi Informasi Komputer Universitas Serang Raya \\ ${ }_{2}^{2}$ Program Studi Rekayasa Sistem Komputer Fakultas Teknologi Informasi Komputer Universitas Serang Raya \\ Jln. Raya Cilegon Serang - Drangong Kota Serang \\ 1dedi@unsera.ac.id, \\ ${ }^{2}$ salehdwiyatno@gmail.com, \\ ${ }^{3}$ sulistiyonoputro@gmail.com
}

\begin{abstract}
Abstrak - Penelitian ini tentang pembuatan aplikasi Virtual Tour pada Museum Negeri Banten, permasalahan dalam penelitian ini adalah bagaimana membuat sebuah aplikasi menarik yang dapat digunakan di sebuah Museum agar dapat memberikan sensasi baru ketika berkunjung ke Museum. Pengembangan aplikasi menggunakan metode Luther-Sutopo yaitu Multimedia Development Life Cycle (MDLC) yang terdiri dari 6 tahapan antara lain concept, desain, material collecting, assemmbly, testing, dan distribution. Dalam proses perancangannya, dilakukan kombinasi antara gambar panorama $360^{\circ}$ dengan gambar, teks dan musik sehingga pengguna dapat melihat informasi visual secara mudah. Tahap pembuatan aplikasi dengan Tourweaver, Coreldraw dan Photoshop sedangkan untuk pengujian aplikasi dilakukan menggunakan blackbox system.
\end{abstract}

Kata Kunci: Virtual Tour, Virtual Reality, Museum Negeri, ICT Pembelajaran, Research and Development

\section{PENDAHULUAN}

Museum Negeri Banten diresmikan pada tanggal 29 Oktober 2015 berstatus Bangunan Cagar Budaya. Berdasarkan data pengunjung Museum selama periode Triwulan III, dari bulan Januari 2019 sampai dengan Agustus 2019 mengalami masalah penurunan pengunjung. Pada bulan Januari 2019 sebanyak 1.371, pada bulan Juli 2019 mengalami penurunan menjadi 1.004 orang, sedangkan pada bulan Agustus 2019 sebanyak 724 orang. Salah satu kemungkinan permasalahannya adalah kurangnya promosi Museum. Belum ada kegiatan promosi dilakukan oleh Museum kepada masyarakat baik dengan cara membuat poster atau berupa katalog atau kegiatan lain untuk menarik pengunjung agar datang ke Museum.

Perkembangan teknologi komunikasi dan informasi yang cepat muncul berbagai macam aplikasi-aplikasi menarik berbasis smartphone. Salah satunya adalah Virtual tour dan Virtual Reality yang dapat dimanfaatkan sebagai media informasi sekaligus media promosi yang cukup menarik.

Menurut (Wulur : 2015), Virtual Tour merupakan sebuah simulasi dari sebuah lokasi yang terdiri dari rentetan gambar. Yang digabungkan (stitch) untuk menghasilkan foto panorama $360^{\circ}$, dan dapat memberi pengalaman 'pernah berada' di suatu tempat hanya dengan melihat layar monitor. Dalam aplikasi Virtual Tour Museum ini pengunjung dapat melihat lingkungan Museum secara visual dengan pandangan panorama $360^{\circ}$. Selain itu, pengguna juga dapat merasakan sensasi berjalan-jalan ke beberapa lokasi yang ada di Museum Negeri Provinsi Banten dengan aplikasi virtual tour.

Berdasarkan uraian yang telah dipaparkan pada latar belakang, maka rumusan masalah yang akan diselesaikan adalah

a) Bagaimana membuat media promosi museum yang lebih menarik?

b) Bagaimana perancangan dan pembuatan aplikasi virtual tour pada Museum Negeri Banten?.

\section{METODOLOGI PENELITIAN}

Tujuan utama penelitian ini adalah merancang dan membuat aplikasi menggunakan teknologi Virtual Tour dengan memanfaatkan video dan gambar yang di format ke dalam bentuk panorama $360^{\circ}$. terlihat pada skema gambar 1. 


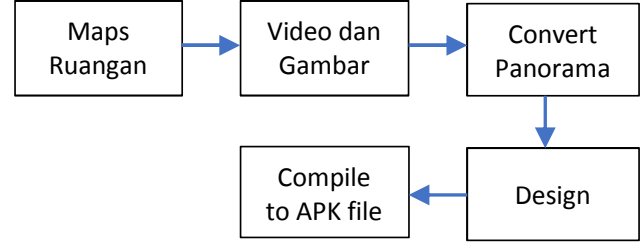

Gambar 1 Tahapan Penelitian

Berikut penjelasan detil kegiatan dari setiap tahapan yang ada pada gambar 1 .

(1) Tahap pertama. Kegiatan yang akan dilakukan pada tahap pertama ini meliputi: (a) mendapatkan data ruangan yang ada pada Museum Negeri Banten. (b) menyusun denah ruangan ke dalam bentuk peta ruang

(2) Tahap kedua. Setelah tersusun peta ruang, kemudian dilakukan mengumpulan bahan video dan gambar yaitu dengan melakukan capture video dan capture gambar ruangan.

(3) Tahap ke Tiga. Melakukan konversi dari video dan gambar yang sudah didapat ke dalam bentuk panorama dengan menggunakan aplikasai Panaview.

(4) Tahap ke Empat. dilakukan desain aplikasi, semua gambar yang sudah di konversi ke dalam bentuk panorama di susun sesuai dengan skema aplikasi yang ada pada Panaview dan ditampilkan menggunakan aplikasi Tourviewer

(5) Tahap ke Lima. Agar aplikasi dapat ditampilkan pada smartphone, maka (a) dilakukan compile ke dalam bentuk file yang ber extensi APK. (b) file APK di simpan pada google drive dan dilakukan share (c) melakukan download dari googledrive (d) melakukan instalasi aplikasi dan siap dijalankan.

Penelitian ini mengambil lokasi di Museum Negeri Banten yang terletak di bekas pendopo Kota Serang, penelitian dilakukan pada tahun 2020 .

Variabel yang diukur dan diamati dalam penelitian yaitu bangun ruang Museum Negeri Banten, Ruangan yang ada, benda pada Museum, pencahayaan ruangan, pencahayaan benda Museum.

Penelitian ini merupakan jenis penelitian kualitatif dengan lebih menekankan kepada kualitas hasil penelitian. Aplikasi dirancang tidak cukup menggunakan teks saja, melainkan menggunakan fasilitas visualisasi panorama $360^{\circ}$ dengan gambar dan musik. Dalam pembuatan perancangan aplikasi Virtual Tour $360^{\circ}$ menggunakan aplikasi Tourweaver dan menggunakan Metode pengembangan multimedia Luther-Sutopo. Dengan dibuatnya aplikasi ini, diharapkan dapat menjadi sarana informasi seputar gambaran Museum Negeri Provinsi Banten. Berikut sedikit penjelasan rancangan metode Luther-Sutopo.

a. Concept (Konsep). Perancangan Aplikasi Virtual Tour 360o di Museum Negeri Provinsi Banten gambar yang akan digunakan menggunakan foto panorama $360^{\circ}$. Jenis aplikasi yang dibuat yaitu berupa media informasi yang akan digunakan untuk masyarakat umum.

b. Design (Desain / Rancangan). Aplikasi yang dibuat akan di isi dengan beberapa media di antaranya teks, audio, dan gambar yang keseluruhannya akan ditempatkan ke dalam beberapa menu.

c. Material Collecting (Pengumpulan Bahan). Material atau bahan yang akan digunakan adalah gambar panorama 3600 , backsound yang akan digunakan diperoleh dari google. Serta Hardware dan Software yang dibutuhkan untuk aplikasi.

d. Assembly (Penyusunan dan Pembuatan). Menggunakan media perangkat lunak seperti Tourweaver, adobe Photoshop, dan Android Studio.

e. Testing (Uji Coba). Aplikasi ini menggunakan teknik blackbox dengan cara menjalankan setiap halaman, tombol, musik dan animasi.

f. Distribution (Menyebar Luaskan). Aplikasi disimpan dalam media penyimpanan yang akan dikirim ke smartphone melalui kabel data, dan bluetooth

\section{HASIL DAN PEMBAHASAN}

Data kebutuhan aplikasi yang akan digunakan pada penelitian ini adalah :

1) Kebutuhan Perangkat Keras (Hardware)

Hardware digunakan sebagai alat pengolah data yang bekerja untuk mengolah data yang berbentuk teks, gambar, audio dan sebagainya. Konten yang akan ditampilkan dalam aplikasi ini menggunakan panorama $360^{\circ}$, dimana diperlukan smartphone yang baik agar aplikasi ini dapat berjalan dengan baik. Spesifikasi perangkat keras yang dibutuhkan akan dibagi menjadi dua bagian yaitu kebutuhan perangkat keras (Hardware) dalam membangun aplikasi dan kebutuhan perangkat keras (Hardware) bagi pengguna aplikasi. Adapun spesifikasinya dapat dilihat pada tabel 1 dan tabel 2.

Table 1 Spesifikasi PC/Laptop dan Smartphone android

\begin{tabular}{|c|c|c|c|c|}
\hline $\mathrm{NO}$ & Deskripsi & PC/Notebook & $\begin{array}{c}\text { Smarthphone } \\
\text { Android }\end{array}$ & $\begin{array}{c}\text { Kamera } \\
360^{\circ} \\
\end{array}$ \\
\hline 1 & Layar & $\begin{array}{l}\text { Layar } 14 \text { Inch } \\
\text { dengan resolusi } \\
1366 \times 768\end{array}$ & $\begin{array}{lr}\text { Layar } & 5.0 \\
\text { Resolusi } & 1280 \\
x \quad 720 \text { pixels } \\
\text { atau lebih }\end{array}$ & - \\
\hline 2 & Processor & Intel i3-3110M & $\begin{array}{l}\text { Chipset } \\
\text { Snapdragon } \\
\text { 430, CPU Octa } \\
\text { Core, Quad } \\
\text { Core 1.5 GHz } \\
\text { Cortex - A53 } \\
\text { atau lebih }\end{array}$ & - \\
\hline 3 & Memory & $\begin{array}{l}\text { RAM } \\
2 \text { GB }\end{array}$ & $\begin{array}{l}\text { RAM } 3 \text { GB } \\
\text { atau lebih }\end{array}$ & - \\
\hline 4 & OS & $\begin{array}{l}\text { Windows } 10 \\
\text { Home }\end{array}$ & $\begin{array}{l}\text { Android } \quad 5.1 \\
\text { Lollipop }\end{array}$ & - \\
\hline 5 & VGA & $\begin{array}{l}\text { Graphics } \\
\text { Processor } \\
\text { Integrated vidia } \\
\text { N14M-GE Intel } \\
\text { HD Graphic }\end{array}$ & $\begin{array}{l}\text { GPU Adreno } \\
405 \text { atau lebih }\end{array}$ & - \\
\hline 5 & $\begin{array}{l}\text { Hard } \\
\text { Drive }\end{array}$ & 500 GB HDD & $\begin{array}{l}32 \\
\text { Memory } \\
\text { Internal }\end{array}$ & $\begin{array}{l}8 \mathrm{~GB} \\
\text { Memory } \\
\text { Internal }\end{array}$ \\
\hline
\end{tabular}

Table 2 Rincian Biaya Hardware dan Software $\begin{array}{lllll}\text { No. Jenis } & \text { Satuan } & \text { Harga } & \text { Jumlah }\end{array}$ 


\begin{tabular}{|c|c|c|c|c|}
\hline 1. & Laptop & 1 & Rp. 4.799 .000 & Rp. 4.799.000 \\
\hline 2. & Smartphone & 1 & Rp. 3.500 .000 & Rp. 3.500 .000 \\
\hline 3. & Kamera $360^{\circ}$ & 1 & Rp. 5.050 .000 & Rp. 5.050 .000 \\
\hline umber & \multicolumn{4}{|c|}{$\begin{array}{l}\text { : http://tabloidlaptop.com (Diakses :14 Januari 2019) } \\
\text { http://arenasmartphone.com (Diakses }: 14 \text { Januari } \\
\text { 2019) } \quad \text { http://plazakamera.com/shop/ricoh-theta-s/ } \\
\text { (Diakses : 14 Januari 2019) }\end{array}$} \\
\hline
\end{tabular}

2) Kebutuhan Perangkat Lunak (Software)

Software yang diperlukan dalam pembuatan Aplikasi Virtual Tour $360^{\circ}$ di Museum Negeri Provinsi Banten ini adalah sebagai berikut :
(a) Sistem Operasi: Microsoft Windows 10 Pro 64- bit Sistem operasi yang ada pada PC/Laptop.
(b) Java Development Kit (JDK) Tools pengembangan bahasa pemrograman bahasa java.
(c) Android Studio Software Development (SDK) Tools pengembangan program android.
(d) Tourweaver merupakan aplikasi yang digunakan sebagai software untuk merancang aplikasi Virtual Tour $360^{\circ}$ di Museum Negeri Provinsi Banten.
(e) Photosop CS6 merupakan aplikasi yang digunakan untik mengedit, membuat gambar yang akan digunakan untuk aplikasi ini.

3). Kebutuhan data aplikasi pada penelitian ini adalah :

(a) Teks yang dibutuhkan pada aplikasi ini diperoleh dari pihak Museum Negeri Provinsi Banten.

(b) Gambar ; Dalam pembuatan Aplikai Virtual Tour $360^{\circ}$ di Museum Negeri Provinsi Banten dibutuhkan beberapa gambar panorama $360^{\circ}$ dan beberapa gambar pendukung agar membuat aplikasi ini lebih terlihat menarik bagi para penggunanya.

\section{Perancangan (Design)}

Setelah merancang konsep, kemudian dapat dirancang isi mengenai apa yang akan disampaikan pada aplikasi ini. Rancangan isi yang dimasukan ke dalam informasi yang disampaikan harus sesuai dengan konsep yang disusun serta tidak menyimpang dari tujuan dibuatnya aplikasi ini. Aplikadsi yang dibuat akan di isi dengan beberapa media di antaranya teks, audio, dan gambar. yang keseluruhan akan ditempatkan ke dalam beberapa menu.

\section{Perancangan Struktur Navigasi}

Struktur navigasi yang digunakan adalah model hierarki. struktur atau alur dari suatu program dan dapat membantu mengorganisasikan seluruh elemen pembuatan program aplikasi. Berikut ini merupakan rancangan struktur navigasi untuk Aplikasi Virtual Tour $360^{\circ}$.di Museum Negeri Provinsi Banten :

Dari struktur Navigasi pada gambar 2 menjelaskan bahwa tampilan awal dalam aplikasi ini adalah halaman pembuka atau loading, yang akan langsung masuk ke menu utama. Pada halaman menu utama terdapat beberapa tombol diantaranya adalah tombol Mulai, tombol Alat, tombol Musik, dan tombol Tentang.
Pada tahap Collecting Material, dilakukan 3 tahapan yaitu Capturing, Editing dan Rendering.

1. Untuk proses capturing yaitu dengan melakukan mengcapture atau memfoto dengan digital camera dengan mode Foto Panorama.

a. Foto panorama yang digunakan adalah jenis foto panorama silinder (Cylindrical). Proses foto dilakukan dengan cara memutar secara 3600, kemudian akan dilakukan proses edit menggunakan aplikasi editing foto.

b. Dilakukan proses perekaman suara yang disesuaikan dengan situasi dan kondisi ketika ada di ruangan Museum. User dapat memilih suara latar atau backsound sesuai dengan keinginannya.

2. Pada proses editing dilakukan pemindahan secara digital dari foto-foto yang sudah diambil pada saat proses capturing. Kemudian dengan aplikasi editing video dilakukan proses koreksi, kondensasi, organisasi dan modifikasi sehingga menghasilkan output yang dapat dinikmati menggunakan aplikasi Virtual Tour.

3. Proses rendering merupakan tahap akhir dari pembuatan aplikasi virtual tour.
a. Rendering foto panorama
b. Rendering video objek Museum
c. Final rendering.

Hasil render akan diaplikasikan menggunakan html5. Hal ini dimaksudkan agar aplikasi dapat dibuka menggunakan web browser yang dapat di akses baik dari desktop maupun dari mobile. 


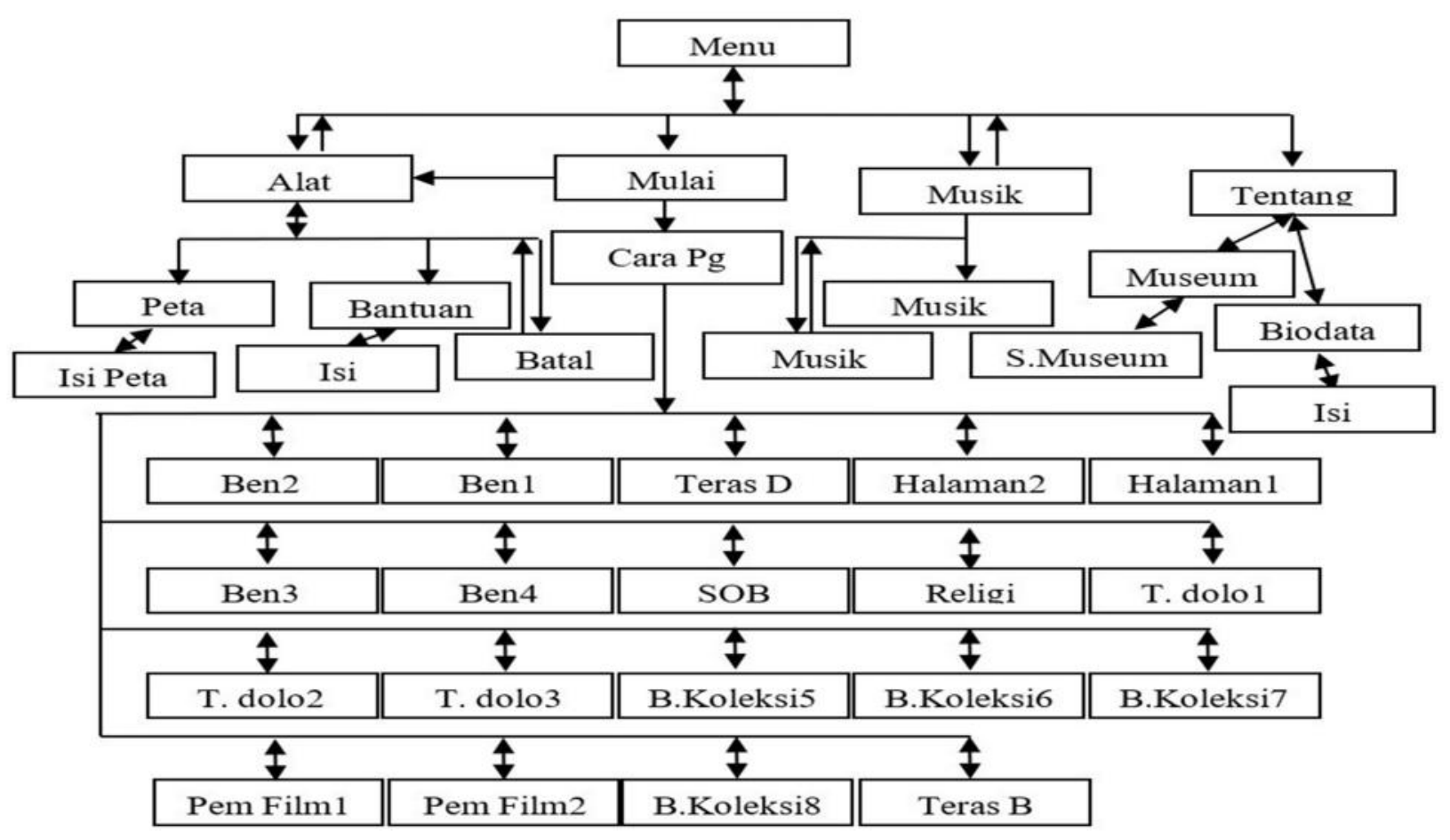

Gambar 2 Struktur Navigasi Model Hierarki
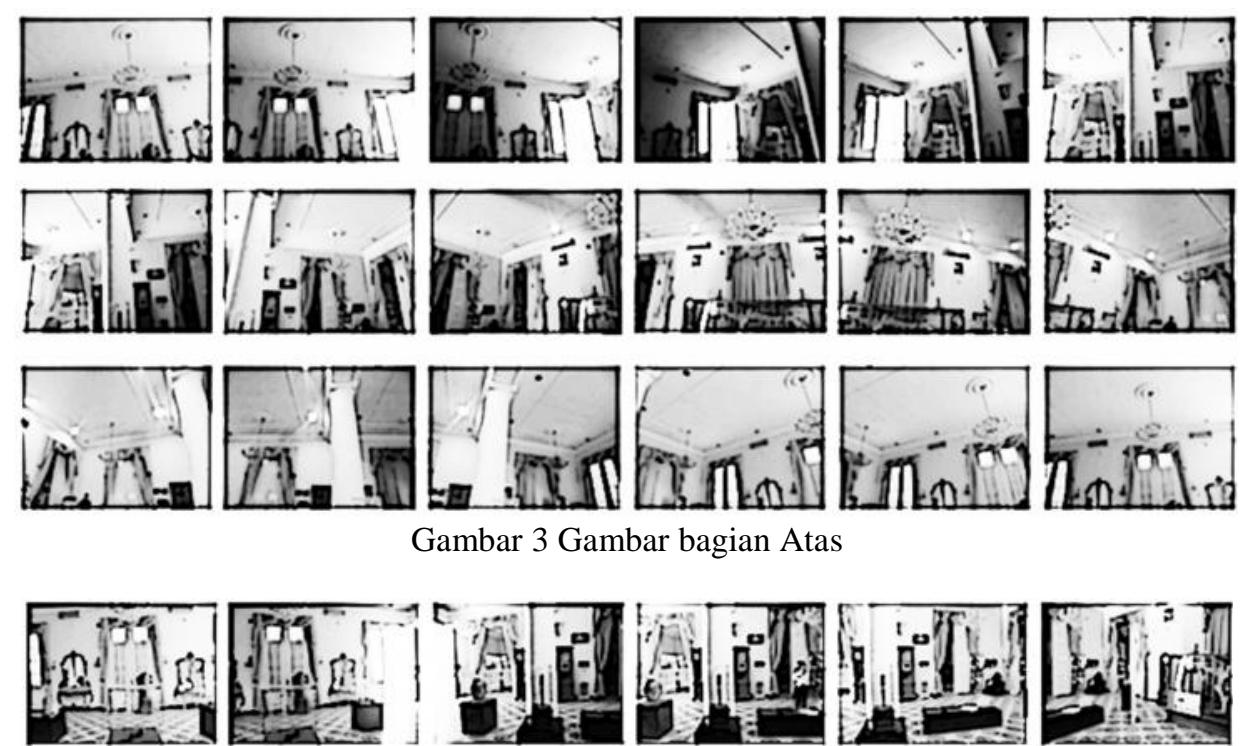

Gambar 3 Gambar bagian Atas
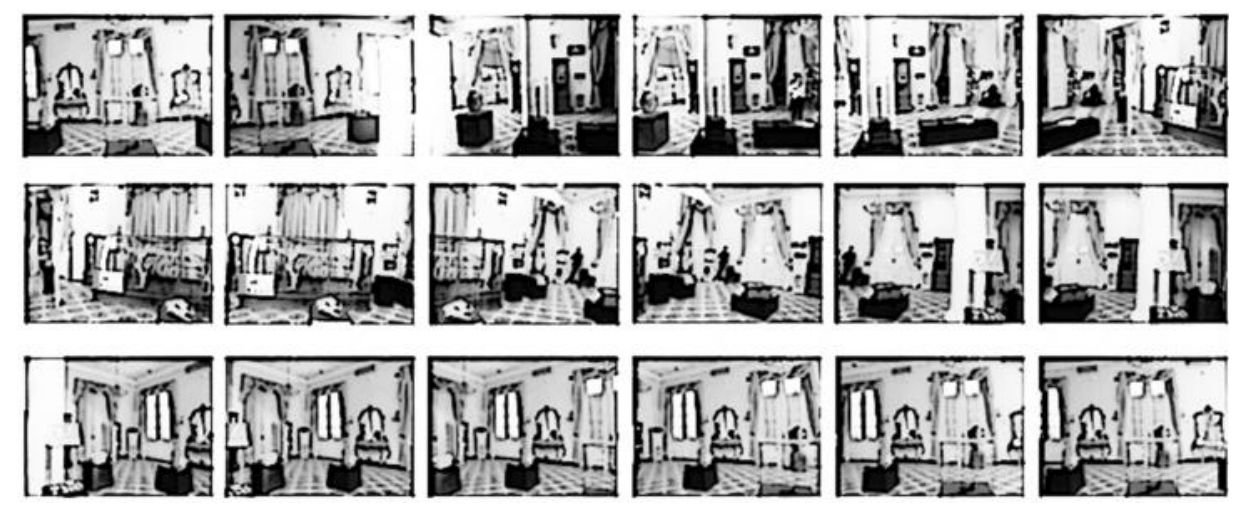

Gambar 4 Bagian Tengah 


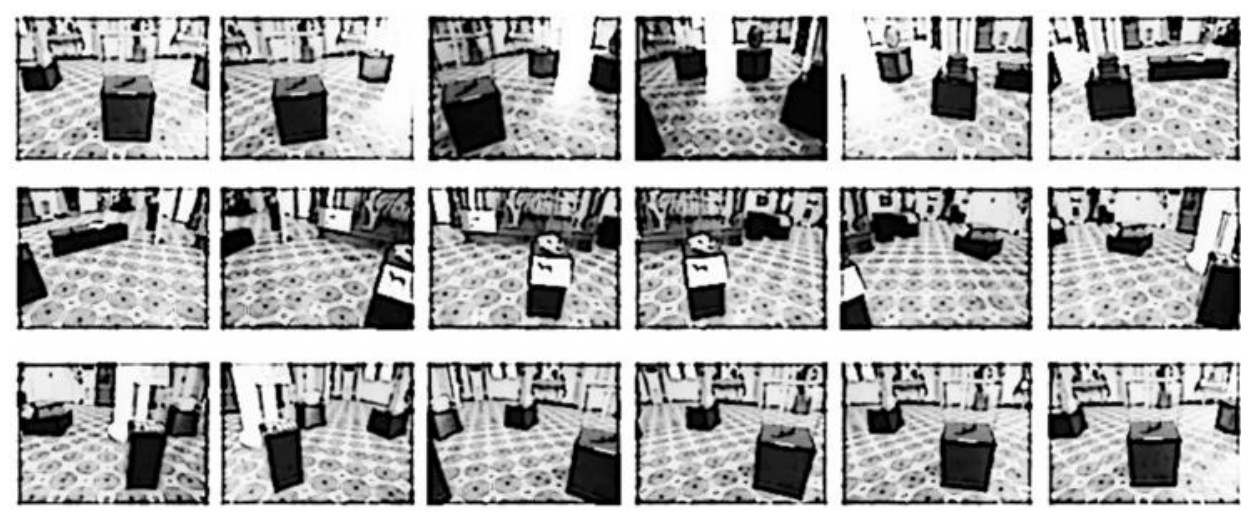

Gambar 5 Bagian Bawah

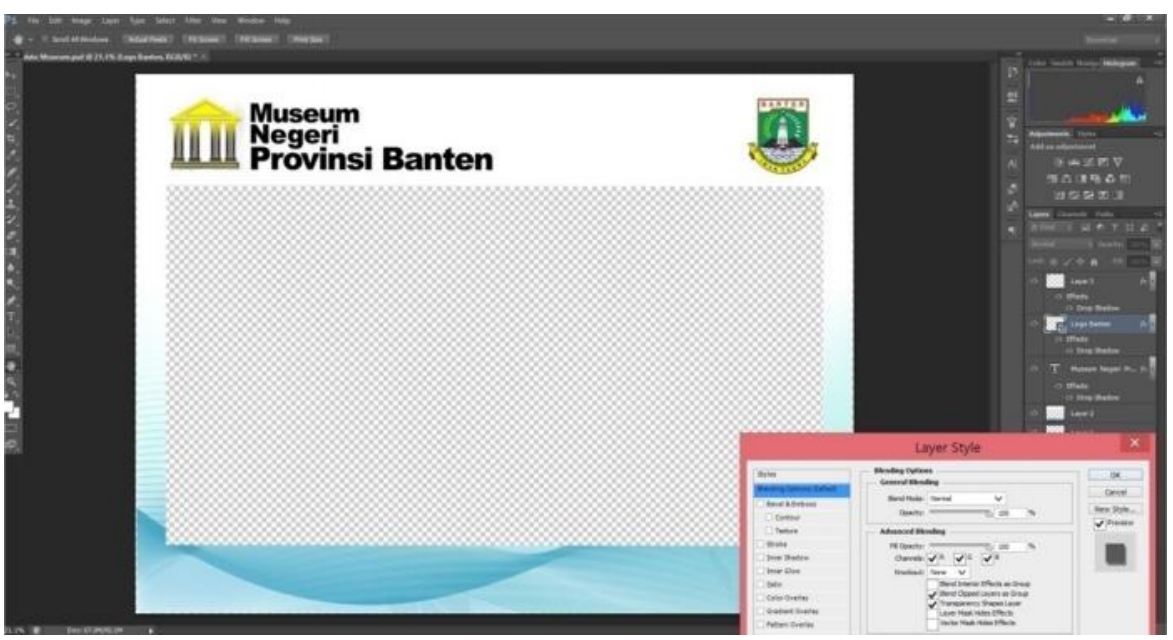

Gambar 1 Editing Template

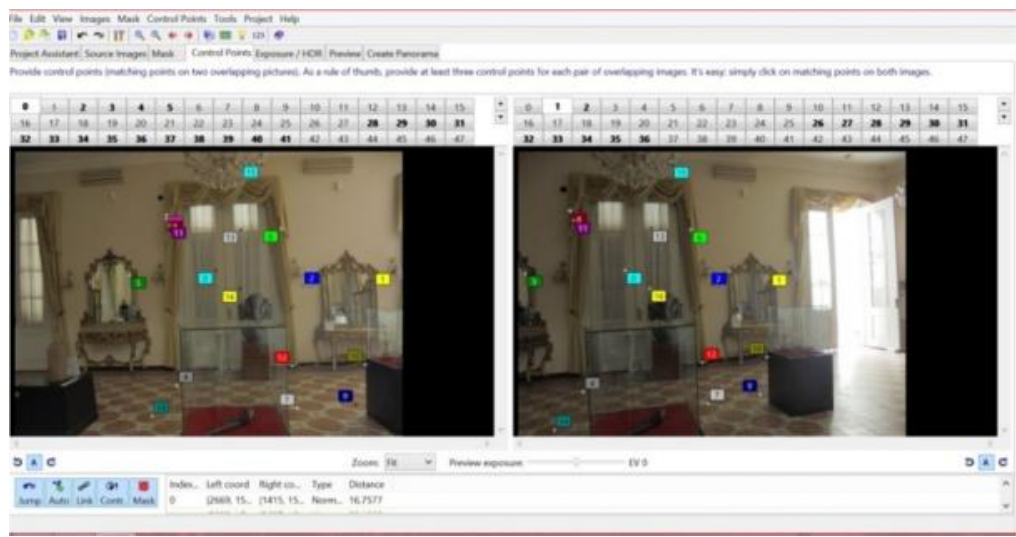

Gambar 7 Image Stitching

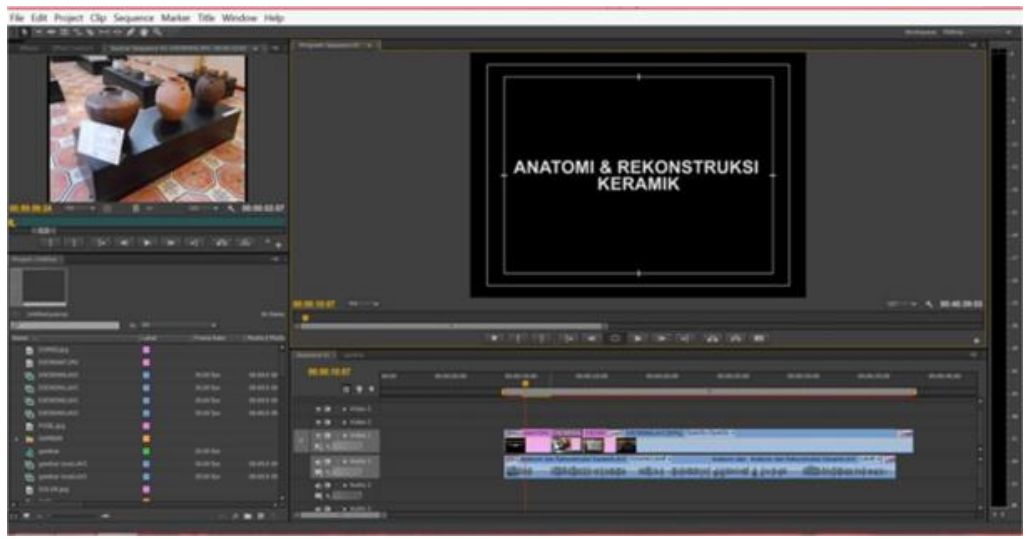


Gambar 8 Editing Video

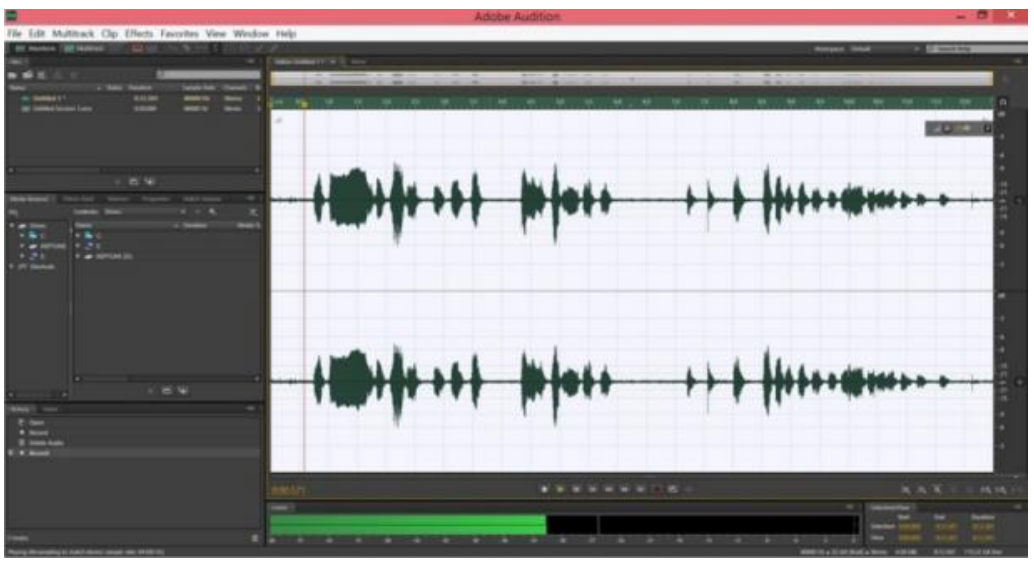

Gambar 9 Editing Audio

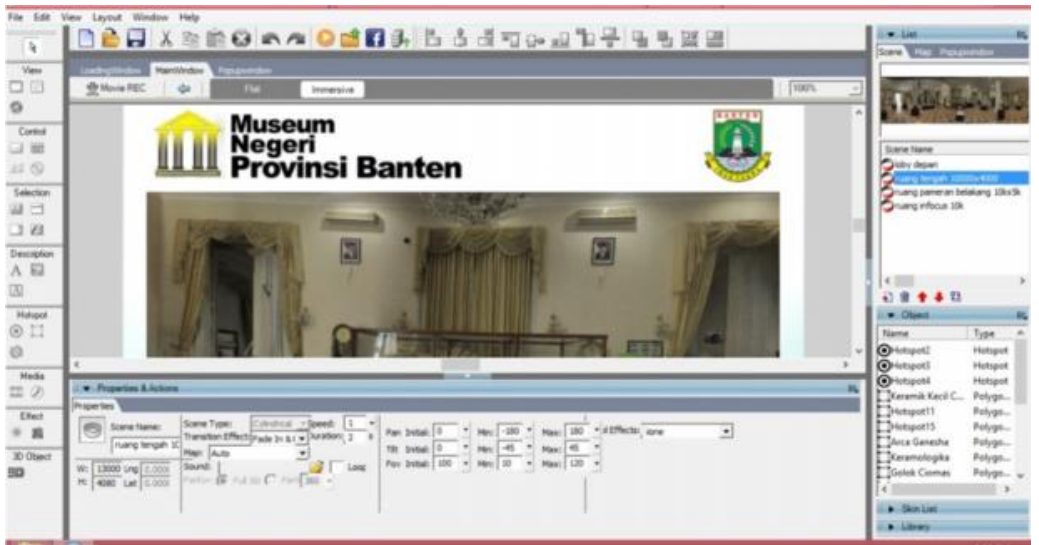

Gambar 102 Editing Hotspot

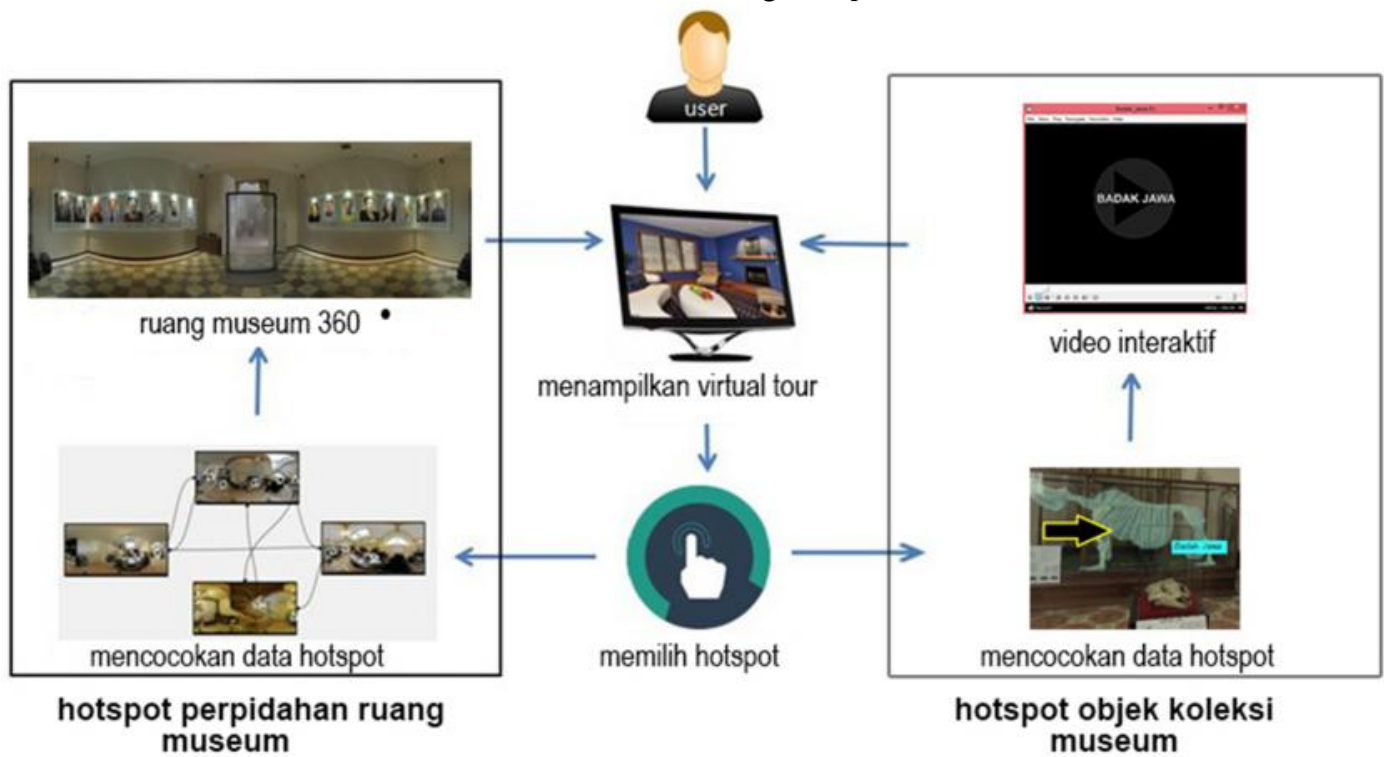

Gambar 11 Arsitektur komputer aplikasi Virtual Reality

Hasil dari kegiatan ini adalah terciptanya sebuah aplikasi multimedia dengan metode Virtual Tour. Aplikasi dibuat menggunakan software Easypano Tourweaver. Aplikasi dapat digunakan dengan web browser baik pada desktop maupun smartphone. 


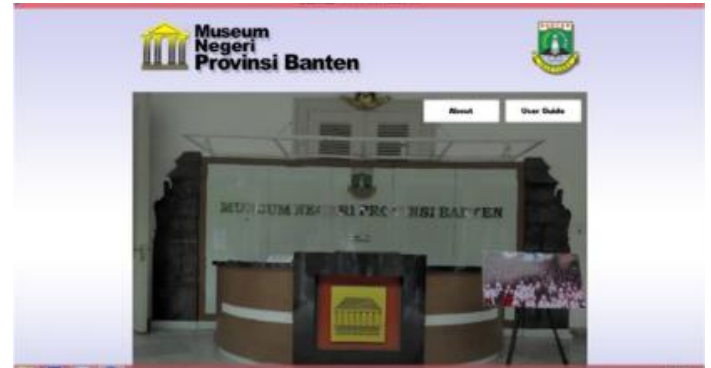

Gambar 312 Ruang Lobby Museum

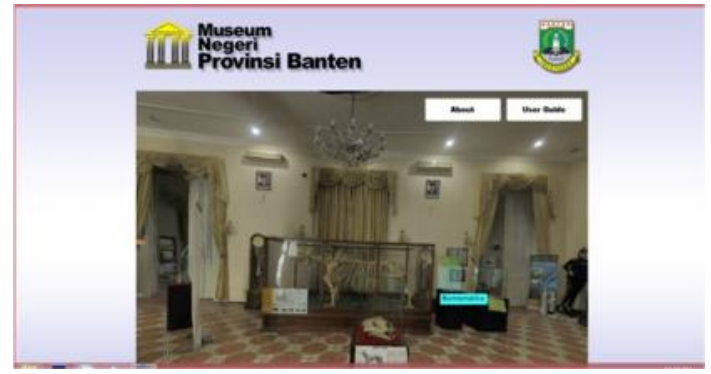

Gambar 13 Ruang koleksi museum

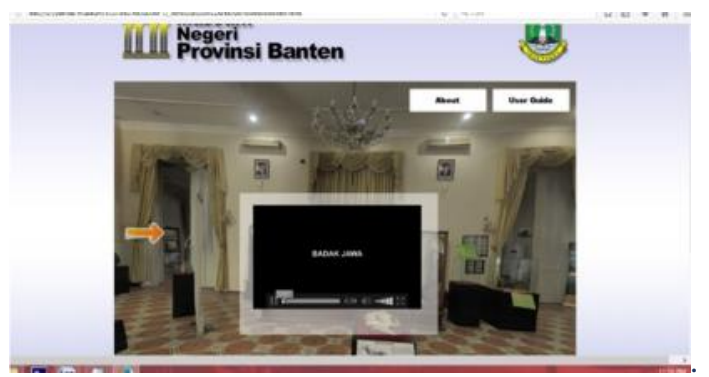

Gambar 14 Jendela Рорир

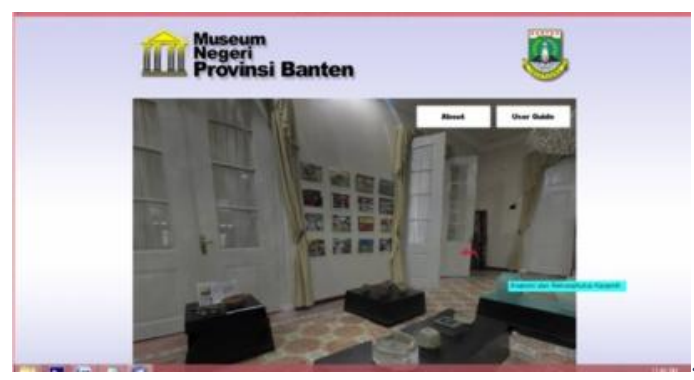

Gambar 15 Ruang Koleksi Belakang

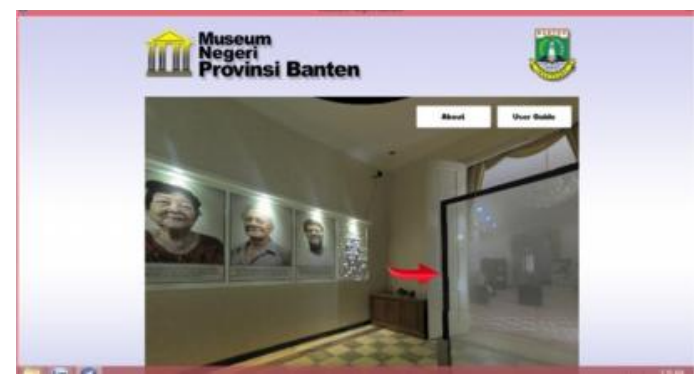

Gambar 16 Ruang Opini Banten

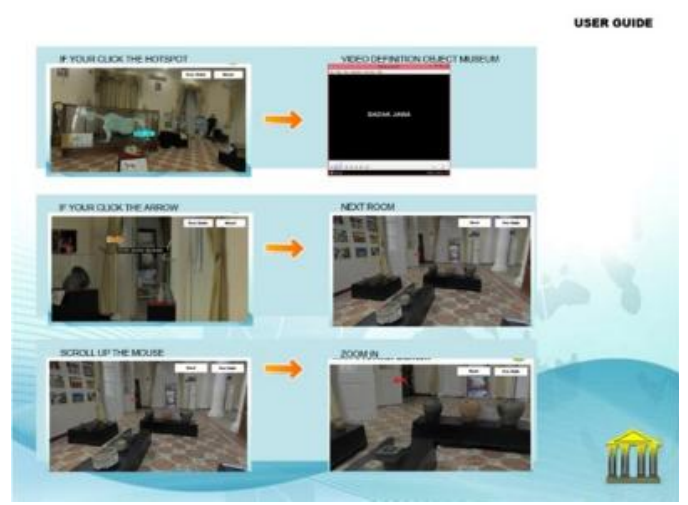

Gambar 17 User Guide

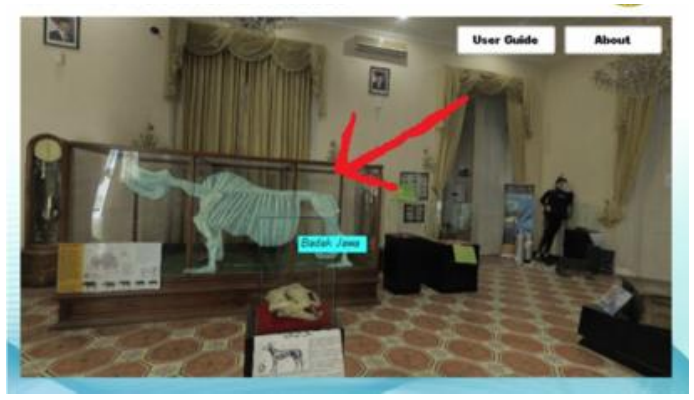

Gambar 18 Hotspot Objek Museum

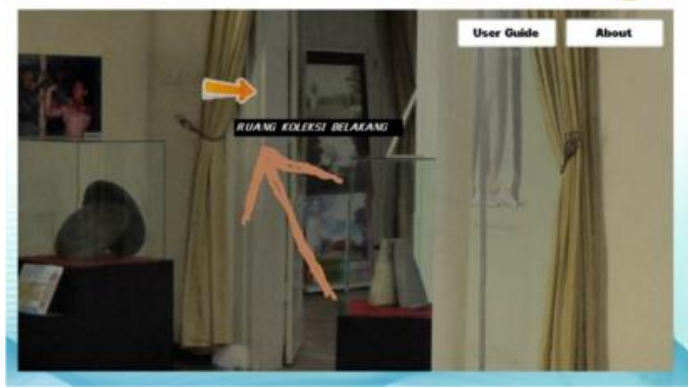

Gambar 19 Hotspot penunjuk arah

\section{KESIMPULAN}

Beberapa poin yang dapat disimpulkan dari hasil sementara penelitian ini diantaranya yaitu:

1. Perancangan aplikasi Virtual Tour ini telah berhasil dibuat sebagai media informasi dan promosi di Museum Negeri Banten.

2. Aplikasi ini dirancang sesuai dengan konsep yang telah dibuat yaitu menjelaskan tentang gambaran ruangan-ruangan yang ada di Museum Negeri Provinsi Banten dengan menggunakan panorama $360^{\circ}$, sehingga pengguna merasa berada diruangan tersebut. Aplikasi ini dibangun dengan menggunakan tahapantahapan metodelogi pengembangan Multimedia Luther-Sutopo. Dan dengan menggunakan softwaresoftware yang diperlukan untuk merancang aplikasi ini seperti Tourweaver, dan Photoshop. Aplikasi Virtual Tour ini agar aplikasi dapat dijalankan dengan baik. 


\section{REFERENSI}

[1] Adeleke, M. A. (2007). Strategic Improvement of Mathematical Problem-Solving Performance of Secondary School Students Using Procedural and Conceptual Learning Strategies. Educational Research and Review, 2 (9), 259-263.

[2] Argubright, M. (2014). Comparing Traditional Math Instruction to Online Instruction: Preparing Students for the Kansas College and Career Ready Standards. Kansas: University of Kansas.

[3] Ashburn, E. A. \& Floden, R. E. (2006). Meaningful Learning Using Technology: What Educators Need to Know and Do. New York: Teachers College Press.

[4] Aziz, Z. \& Hossain, M. A. (2010). A Comparison of Cooperative Learning and Conventional Teaching on Students' Achievement in

Secondary Mathematics. Procedia Social and Behavioral Sciences, 9, 53-62.

[5] Bakker, A. (2004). Design research in statistics education: On symbolizing and computer tools. Utrecht: Freudenthal Institute.

[6] Bishara, S. (2015). Active and Traditional Teaching of Mathematics in Special Education. Creative Education, 6, 2313-2324. Diakses di http://dx.doi.org/10.4236/ce.2015.622238

[7] Brehmer, D. (2015). Problem Solving in Mathematics Textbooks. Sweden: Malardalen University.

[8] Cave, A. (2010). Learning Math in Second Grade: An Application of Cognitive Apprenticeship. National Forum of Applied Educational Research Journal, 23 (3), 1-16.

[9] CBSE (Central Board of Secondary Education). (2010). Life Skills Education. India: Shiksha Kendra Community Centre.

[10] Central Board of Secondary Education (CBSE). (2010). Life Skills Education. India: Shiksha Kendra Community Centre.

[11] Cohen, L., Manion, L. \& Morrison, K. (2011). Research methods in education (7th ed.). London: Routledge.

[12] Creswell, J. W. (2014). Research design. qualitative, quantitative and mixed method approaches (4th ed.). Thousand Oaks: CA Sage.

[13] Curri, E. (2012). Using Computer Technology in Teaching and Learning Mathematics in an Albanian Upper Secondary School. Kristiansand: University of Agde 